\title{
Association of intraoperative circulating-brain injury biomarker and neurodevelopmental outcomes at 1 year among neonates who have undergone cardiac surgery
}

Eric M. Graham, MD, ${ }^{a}$ Renee' H. Martin, PhD, ${ }^{b}$ Andrew M. Atz, MD, ${ }^{a}$ Kasey Hamlin-Smith, PhD, ${ }^{c}$ Minoo N. Kavarana, MD, ${ }^{\mathrm{d}}$ Scott M. Bradley, MD, ${ }^{\mathrm{d}}$ Bahaaldin Alsoufi, MD, William T. Mahle, MD, ${ }^{\mathrm{f}}$ and Allen D. Everett, $\mathrm{MD}^{\mathrm{g}}$

\section{ABSTRACT}

Background: Neurodevelopmental disability is the most significant complication for survivors of infant surgery for congenital heart disease. In this study we sought to determine if perioperative circulating brain injury biomarker levels are associated with neurodevelopmental outcomes at 12 months.

Methods: A secondary analysis of a randomized controlled trial of neonates who underwent cardiac surgery was performed. Glial fibrillary acidic protein (GFAP) was measured: (1) before skin incision; (2) immediately after bypass; (3) 4 and (4) 24 hours postoperatively. Linear regression models were used to determine an association with the highest levels of GFAP and Bayley Scales of Infant and Toddler Development third edition (BSID) composite scores.

Results: There were 97 subjects who had cardiac surgery at a mean age of $9 \pm 6$ days and completed a BSID at $12.5 \pm 0.6$ months of age. Median (25th-75th percentile) levels of GFAP were 0.01 (0.01-0.02), 0.85 (0.40-1.55), $0.07(0.05-0.11)$, and $0.03(0.02-0.04) \mathrm{ng} / \mathrm{mL}$ at the 4 time points, respectively. In univariate analysis GFAP was negatively associated with cognitive, language, and motor composite scores. GFAP levels immediately after bypass differed between institutions; $1.57(0.92-2.48)$ versus $0.77(0.36-1.21) \mathrm{ng} / \mathrm{mL}(P=.01)$. After adjusting for center and potential confounders, GFAP was independently associated with BSID motor score $(P=.04)$.

Conclusions: Higher GFAP levels at the time of neonatal cardiac operations were independently associated with decreased BSID motor scores at 12 months. GFAP might serve as a diagnostic means to acutely identify perioperative brain-specific injury and serve as a benchmark of therapeutic efficacy for investigational treatments, discriminate center-specific effects, and provide early prognostic

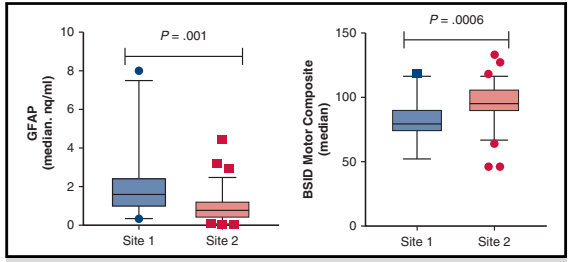

Post-bypass GFAP differs according to site and is associated with worse neurodevelopment at 12 months

\section{Central Message}

In this multicenter study, higher plasma glial fibrillary acidic protein level at the time of neonatal cardiac operations was associated with worse 1-year neurodevelopmental assessment.

\section{Perspective}

Neurodevelopmental disability is the most significant complication for survivors of infant surgery for congenital heart disease. Higher plasma glial fibrillary acidic protein level at the time of neonatal cardiac operations is associated with worse neurodevelopmental assessment at 12 months of age. Glial fibrillary acidic protein might serve as a diagnostic means to acutely identify perioperative brain injury.

See Commentary on page 2003. information for intervention. (J Thorac Cardiovasc Surg 2019;157:1996-2002)

\footnotetext{
From the ${ }^{\mathrm{a}}$ Division of Pediatric Cardiology, Department of Pediatrics, and Departments of ${ }^{b}$ Public Health Sciences, ${ }^{c}$ Pediatrics, and ${ }^{d}$ Cardiothoracic Surgery, Medical University of South Carolina, Charleston, SC; ${ }^{\mathrm{e}}$ Department of Cardiothoracic Surgery and ${ }^{\mathrm{f}}$ Division of Pediatric Cardiology, Department of Pediatrics, Children's Healthcare of Atlanta and Emory University, Atlanta, Ga; and ${ }^{\mathrm{g}}$ Division of Cardiology, Department of Pediatrics, Johns Hopkins University, Baltimore, Md.

This work was supported in part by grant HL112968 from the National Heart, Lung, and Blood Institute. This work is solely the responsibility of the authors and does not necessarily represent the official views of National Heart, Lung, and Blood Institute or the National Institutes of Health.

Received for publication Aug 16, 2018; revisions received Dec 19, 2018; accepted for publication Jan 12, 2019; available ahead of print Feb 20, 2019.

Address for reprints: Eric M. Graham, MD, Children's Heart Center, 165 Ashley Ave, MSC 915, Charleston, SC 29425 (E-mail: grahamem@musc.edu).

$0022-5223 / \$ 36.00$

Copyright (c) 2019 by The American Association for Thoracic Surgery

https://doi.org/10.1016/j.jtcvs.2019.01.040
}

Neurodevelopmental disability is the most significant complication for survivors of infant surgery for congenital heart disease. ${ }^{1-3}$ Children who have undergone cardiac surgery as an infant have been found to have more problems with motor, language and social skills, reasoning, executive function, inattention, and impulsive behavior than their peers without heart disease..$^{4-7}$ These disabilities can ultimately limit educational and employment opportunities, challenge interpersonal relationships, and diminish quality of life. Neurodevelopmental and behavioral impairment have become so pervasive that in 2012 the American Heart Association and the American Academy of Pediatrics issued a joint scientific statement on guidelines for systematic surveillance, screening, 


\section{Abbreviations and Acronyms \\ BSID $=$ Bayley Scales of Infant and Toddler \\ Development third edition \\ $\mathrm{CPB}=$ cardiopulmonary bypass \\ GFAP $=$ glial fibrillary acidic protein \\ NIRS $=$ near-infrared spectroscopy \\ STAT $=$ Society of Thoracic Surgery-European \\ Association for Cardio-Thoracic Surgery}

evaluation, and management of developmental disabilities in an effort to optimize neurodevelopmental outcomes in this population.?

The cause of this disability is multifactorial including innate patient, sociodemographic, and perioperative factors known and unknown and as a result the ability to detect brain injury in real time remains elusive. ${ }^{2,4}$ There is a need to develop simple, objective, point of care diagnostic brain injury biomarkers to predict neurodevelopmental outcomes and provide a possible outcome variable to test new neuroprotection therapies. One candidate biomarker is glial fibrillary acidic protein (GFAP), an astrocyte intermediate filament protein, normally absent in blood and released as a result of astrocyte injury or necrosis. ${ }^{8}$ GFAP levels measured acutely in adults with traumatic brain injury and those surviving cardiac arrest have been associated with neurological disability. ${ }^{9-11}$ The US Food and Drug Administration recently approved (February 14, 2018) the Banyan Brain Trauma Indicator, which measures the levels of 2 brain injury biomarkers, one of which is GFAP (https://www.fda.gov/NewsEvents/ Newsroom/PressAnnouncements/ucm596531.htm). This provides the first commercially available blood test to detect brain injury during concussions. However, an association of GFAP with longer-term neurodevelopmental outcomes specifically in neonates undergoing cardiac surgery has not been explored. Accordingly the objective of this study was to determine if perioperative circulating GFAP levels in neonates undergoing cardiac surgery with cardiopulmonary bypass (CPB) were associated with neurodevelopmental outcomes at 12 months of age.

\section{METHODS \\ Subjects}

Patients were recruited from 2 centers in North America participating in the National Heart, Lung, and Blood Institute-funded Corticosteroid Therapy in Neonates Undergoing Cardiopulmonary Bypass randomized controlled trial of the use of intraoperative methylprednisolone compared with placebo (the study is registered at ClinicalTrials.gov: NCT01579513).

Inclusion criteria for the parent study consisted of infants younger than 1 month of age undergoing cardiac surgery with CPB. Exclusion criteria included prematurity defined as $<37$ weeks post gestational age at the time of surgery, steroids within the 2 days before surgery, suspected infection, or a hypersensitivity that would be a contraindication to methylprednisolone or use of mechanical circulatory support or active resuscitation at the time of proposed randomization. The protocol was approved by the institutional review board at each center, and written informed consent was obtained from a parent/guardian before randomization.

\section{Neurodevelopmental Assessment}

The primary measure of neurodevelopment was assessed at 12 months of age with an in-person evaluation by a trained psychologist experienced with the Bayley Scales of Infant and Toddler Development third edition (BSID). ${ }^{12}$ The BSID is a standardized test for children aged 1 through 42 months and is widely accepted to have good inter-rater reliability. The BSID yields cognitive, language, and motor composite scores. The mean \pm standard deviation for each of the composite scores in the normative population is $100 \pm 15$. Administration of the BSID followed manual guidelines. ${ }^{12}$ The BSID was only administered in English or Spanish, and it was administered in the dominant language spoken in the home. Testing personnel were blinded to the treatment assignment and biomarker results of the subjects.

\section{Study Design and Measurements}

Subjects were randomly assigned to either methylprednisolone at $30 \mathrm{mg} / \mathrm{kg}$ of body weight or placebo at the induction of anesthesia within strata according to planned corrective or palliative operation, with dynamic balancing within surgeon. Whole-blood samples were collected in ethylenediaminetetraacetic acid tubes at 5 perioperative time points. Plasma was isolated by centrifugation, decanted into aliquots, and stored at $-80^{\circ} \mathrm{C}$ until processed for immunoassays. Extensive peri- and postoperative variables were recorded. In all other respects, subjects were managed according to the usual practices at each center. At site 1, full-flow bypass was considered $200 \mathrm{~mL} / \mathrm{kg} / \mathrm{min}$ at $36^{\circ} \mathrm{C}$ and flow is decreased as patient temperature decreases to meet mean arterial pressure goals of 30 to $35 \mathrm{~mm} \mathrm{Hg}$. Generally this resulted in a flow of 80 to $100 \mathrm{~mL} / \mathrm{kg} / \mathrm{min}$ at $18^{\circ} \mathrm{C}$. Regional antegrade cerebral perfusion was used during arch reconstructions either at $18^{\circ} \mathrm{C}$ at a flow of $30 \mathrm{~mL} / \mathrm{kg} / \mathrm{min}$ with monitoring of cerebral near-infrared spectroscopy (NIRS) with a target goal of $>90 \%$; or at $25^{\circ} \mathrm{C}$ at a flow of 60 to $80 \mathrm{~mL} / \mathrm{kg} / \mathrm{min}$ with monitoring of cerebral NIRS, but without a specific target depending on the surgeon. Circulatory arrest was performed at moderate hypothermia (at approximately $25^{\circ} \mathrm{C}$ ), typically for very brief periods, when needed. Cold-blood cardioplegia was given at 45- to 90-minute intervals during periods of aortic cross-clamping. Acid-base management was a pH-stat strategy with a hematocrit goal of $30 \%$ during $\mathrm{CPB}$ at $20^{\circ} \mathrm{C}$ or lower. Alpha-stat management was used for periods of warming. Conventional ultrafiltration was used in all cases. Modified ultrafiltration was used in most cases. At site 2 , general perfusion strategies included full-flow bypass at $2.6 \mathrm{~L} / \mathrm{min} / \mathrm{m}^{2}$ at $32^{\circ} \mathrm{C}$, or low-flow bypass at $1.3 \mathrm{~L} / \mathrm{min} / \mathrm{m}^{2}$ between $20^{\circ} \mathrm{C}$ and $25^{\circ} \mathrm{C}$. Regional antegrade cerebral perfusion was used during aortic arch reconstructions, generally carried out at a temperature of $20^{\circ} \mathrm{C}$ and a flow of $50 \mathrm{~mL} / \mathrm{kg} / \mathrm{min}$, with monitoring of cerebral NIRS with a target goal of $>90 \%$. Cold-blood cardioplegia was given at 20-minute intervals during periods of aortic cross-clamping. Deep hypothermic circulatory arrest was performed at $20^{\circ} \mathrm{C}$, when necessary. Acidbase management was by a $\mathrm{pH}$-stat strategy with a hematocrit goal of $28 \%$ during CPB. Conventional and modified ultrafiltration were used in all cases.

Subjects enrolled in this secondary analysis were included if they completed a BSID and had adequate volume of plasma for measurement of GFAP at the time of this study. GFAP was measured in blood at 4 time points: (1) before skin incision; (2) immediately after the completion of modified ultrafiltration at the end of CPB; (3) at 4 and (4) at 24 hours postoperatively. All samples were batched and assayed simultaneously to avoid potential laboratory assay variance. GFAP was assayed at Johns Hopkins University using an electrochemiluminescent sandwich immunoassay 
as previously described. ${ }^{13-17}$ The lower limit of quantification for the assays was $0.008 \mathrm{ng} / \mathrm{mL}$. The interassay variance at the lower limit of quantification was $11.5 \%$ over the 6 assay plates.

\section{Statistical Analysis}

Standard descriptive statistics were used to summarize the general demographic and clinical data. Continuous demographic characteristics are listed as means and associated standard deviations. Categorical characteristics are expressed as number and percentage of subjects. Simple linear regression models were used to determine an association with highest level of GFAP and BSID cognitive, language, and motor composite scores and between demographic and operating characteristics (age, sex, race, ethnicity, presence of a genetic syndrome, use of deep hypothermic circulatory arrest, duration of $\mathrm{CPB}$, and cross-clamp time) with highest level of GFAP. Linear regression models were developed that adjusted for potential cofounders including center, CPB duration, aortic cross-clamp time, use of deep hypothermic circulatory arrest, and Society of Thoracic SurgeryEuropean Association for Cardio-Thoracic Surgery (STAT) category. ${ }^{18}$ To test differences between centers an independent $t$ test was performed for continuous variables and a $\chi^{2}$ or Fisher exact test for categorical variables. Statistical analyses were performed with SAS, version 9.2 (SAS Institute, Inc, Cary, NC).

\section{RESULTS}

Between June 2012 and June 2017, 97 subjects were enrolled in the primary study and completed a BSID. All 97 subjects had adequate samples for GFAP analysis and comprise this study cohort. Preoperative demographic and operative characteristics are shown in Table 1 . There was a slight male predominance. Mortality risk categories as defined according to STAT categories showed that just over half were STAT 4 with the remaining almost equally divided between STAT 3 and 5 categories. Neurodevelopmental assessment occurred at a mean age of $12.5 \pm 0.6$ months. Mean BSID cognitive composite scores were $105 \pm 15$, for language $101 \pm 13$, and motor scores were $92 \pm 17$.

TABLE 1. Preoperative demographics and operative characteristics

\begin{tabular}{|c|c|c|c|c|}
\hline Variable & $\begin{array}{c}\text { Overall cohort } \\
(\mathbf{n}=97)\end{array}$ & $\begin{array}{c}\text { Site 1 } \\
(n=23)\end{array}$ & $\begin{array}{c}\text { Site } 2 \\
(n=74)\end{array}$ & $P$ value \\
\hline \multicolumn{5}{|l|}{ Age/sex } \\
\hline Mean gestational age at birth, wk & $38.9 \pm 1.3$ & $38.5 \pm 1.4$ & $39.0 \pm 1.2$ & NS \\
\hline Male sex & $56(58)$ & $14(61)$ & $42(57)$ & NS \\
\hline Race/ethnicity & & & & .05 \\
\hline Asian & $2(2)$ & 0 & $2(3)$ & \\
\hline Black or African American & $24(25)$ & $2(9)$ & $22(30)$ & \\
\hline Caucasian & $66(68)$ & $21(91)$ & $45(61)$ & \\
\hline Other & $5(5)$ & 0 & $5(7)$ & \\
\hline Hispanic or Latino & $6(6)$ & $1(4)$ & $5(7)$ & \\
\hline \multicolumn{5}{|l|}{ Diagnosis/procedure } \\
\hline Corrective procedure & 67 (69) & $16(70)$ & $51(69)$ & NS \\
\hline Aortic arch hypoplasia & $11(11)$ & $1(4)$ & $10(13)$ & \\
\hline Transposition of the great arteries & $34(35)$ & $7(30)$ & $27(37)$ & \\
\hline Truncus arteriosus & $6(6)$ & $2(9)$ & $4(5)$ & \\
\hline Other biventricular repair & $16(17)$ & $6(26)$ & $10(14)$ & \\
\hline Palliative procedure & $30(31)$ & $7(30)$ & $23(31)$ & NS \\
\hline Hypoplastic left heart syndrome & $14(14)$ & $4(17)$ & $10(14)$ & \\
\hline Other single ventricle lesions & $7(7)$ & 0 & $7(10)$ & \\
\hline Tetralogy of Fallot pulmonary atresia & $3(3)$ & 0 & $3(4)$ & \\
\hline Other palliative procedure & $6(6)$ & $3(13)$ & $3(4)$ & \\
\hline \multicolumn{5}{|l|}{ Operative characteristics } \\
\hline Age at surgery, $d$ & $9.1 \pm 5.6$ & $7.2 \pm 4.6$ & $9.7 \pm 5.7$ & .06 \\
\hline Weight at surgery, kg & $3.3 \pm 0.5$ & $3.3 \pm 0.5$ & $3.3 \pm 0.5$ & NS \\
\hline STAT 1 & $1(1)$ & 0 & $1(1)$ & NS \\
\hline STAT 2 & $2(2)$ & 0 & $2(3)$ & NS \\
\hline STAT 3 & $23(24)$ & $6(26)$ & $17(23)$ & NS \\
\hline STAT 4 & $52(54)$ & $11(48)$ & $41(55)$ & NS \\
\hline STAT 5 & $19(20)$ & $6(26)$ & $13(18)$ & NS \\
\hline Cardiopulmonary bypass duration, minutes & $185 \pm 62$ & $143 \pm 38$ & $198 \pm 63$ & $<.0001$ \\
\hline Aortic cross clamp, minutes & $82 \pm 42$ & $83 \pm 26$ & $82 \pm 47$ & NS \\
\hline Circulatory arrest & $26(27)$ & $8(35)$ & $18(24)$ & NS \\
\hline Circulatory arrest duration, minutes & $5(0.2-60)$ & $2(0.2-18)$ & $8(2-60)$ & .006 \\
\hline
\end{tabular}

Values are mean \pm standard deviation, median (range), or number (\%) as appropriate. NS, Not significant; STAT, Society of Thoracic Surgery-European Association for CardioThoracic Surgery mortality risk category. 
GFAP levels are depicted in Figure 1. Before skin incision GFAP levels were low. Immediately after completion of CPB there was an almost 100-fold increase. Subsequently there was a 10 -fold decline by 4 hours with a continuing decline at 24 hours postoperatively. In simple linear regression models GFAP at the cessation of CPB was inversely associated with cognitive $\left(R^{2}=0.07\right.$; $P=.01)$, language $\left(R^{2}=0.05 ; P=.03\right)$, and motor $\left(R^{2}=0.09 ; P<.01\right)$ composite scores (Table 2$)$. When the models were adjusted for clinical center, STAT category, CPB duration, aortic cross-clamp time, and use of deep hypothermic circulatory arrest, GFAP at the cessation of CPB was independently associated with motor composite scores $\left(R^{2}=0.22 ; P=.04\right.$; Figure 2). Cognitive and language composite scores were not independently associated with GFAP levels (Table 2). In simple linear regression models age at surgery was inversely associated with GFAP at the cessation of CPB $(P=.02)$, but sex, race, ethnicity, presence of a genetic syndrome, use of deep hypothermic circulatory arrest, duration of $\mathrm{CPB}$, and cross-clamp time were not (data not shown).

\section{Center Differences}

Knowing that recent studies have described center variation in neurodevelopmental outcomes, we examined the relationship between GFAP levels at the cessation of CPB and BSID composite scores according to enrolling site. Figure 3 shows the median (25th-75th percentile) GFAP level was twice as high at one site compared to the other: $1.57(0.92-2.48)$ versus $0.77(0.36-1.21) \mathrm{ng} / \mathrm{mL}(P=.01)$.
This corresponded to lower BSID cognitive $(92 \pm 12$ vs $109 \pm 13 ; P<.0001)$, language $(88 \pm 12$ vs $105 \pm 11$; $P<.0001)$, and motor composite scores $(81 \pm 16$ vs $95 \pm 16 ; P=.0006)$ at site 1 compared with site 2 , respectively. Preoperative demographic and operative characteristics between centers were similar with the exception of a higher percentage of Caucasian infants, younger age at surgery, and shorter CPB and circulatory arrest times at site 1 (Table 1).

\section{DISCUSSION}

\section{Blood-Based Biomarkers and Neurologic Injury}

Blood-based brain biomarkers represent a potentially rapid means of diagnosing neurological injury and GFAP was recently approved by the US Food and Drug Administration as a blood test for concussive brain injury. GFAP is an astrocyte intermediate filament protein, not normally present in blood and represents astrocyte injury or necrosis. Astrocyte foot processes make up the subendothelial component of the blood-brain barrier, thus astrocyte injury biomarkers will also reflect loss of blood-brain barrier integrity. ${ }^{8}$ Elevations in levels of GFAP are detectable within 30 minutes of CPB and are not affected by ultrafiltration. ${ }^{19}$ GFAP levels have been associated with neurological disability in adults with traumatic brain injury and those surviving cardiac arrest. ${ }^{9-11}$ In the pediatric population, circulating GFAP has been shown to be a significant predictor of neurologic injury and hospital survival in children receiving extracorporeal membrane oxygenation, of abnormal magnetic resonance imaging and functional

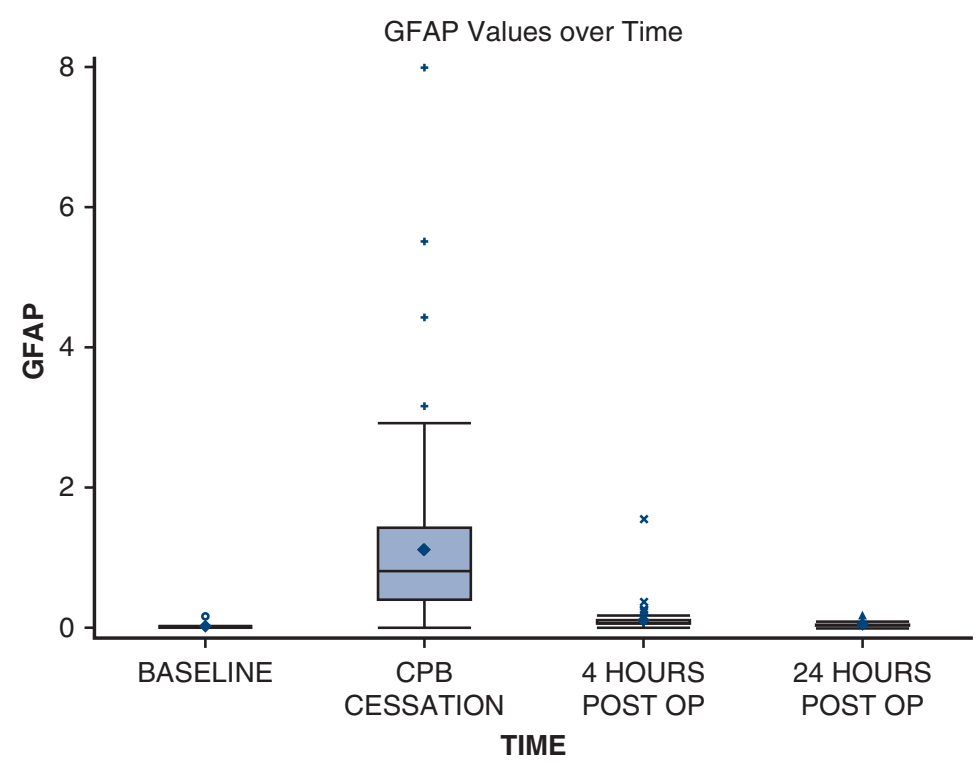

FIGURE 1. Perioperative GFAP levels. Before skin incision GFAP levels were low. Immediately after completion of CPB there was an almost 100-fold increase, followed by a rapid tapering by 4 hours. The upper and lower borders of the box represent the upper and lower quartiles. The middle horizontal line represents the median. The upper and lower whiskers represent the maximum and minimum values of nonoutliers. Extra dots represent outliers. GFAP, Glial fibrillary acidic protein; $C P B$, cardiopulmonary bypass; POST OP, postoperative. 
TABLE 2. Linear regression models for GFAP and Bayley composite scores

\begin{tabular}{|c|c|c|c|c|c|c|c|c|c|c|}
\hline \multirow[b]{2}{*}{ BSID } & \multicolumn{5}{|c|}{ Unadjusted } & \multicolumn{5}{|c|}{ Adjusted } \\
\hline & $\begin{array}{c}\text { Parameter } \\
\text { estimate }\end{array}$ & $\begin{array}{c}\text { Standard } \\
\text { error }\end{array}$ & T value & $R^{2}$ & $P$ value & $\begin{array}{c}\text { Parameter } \\
\text { estimate }\end{array}$ & $\begin{array}{c}\text { Standard } \\
\text { error }\end{array}$ & $\mathbf{T}$ value & $R^{2}$ & $P$ value \\
\hline Cognitive & -3.03 & 1.18 & -2.62 & 0.07 & .01 & -1.43 & 1.15 & -1.24 & 0.34 & .22 \\
\hline Language & -2.50 & 1.13 & -2.23 & 0.05 & .03 & -0.58 & 1.09 & -0.53 & 0.35 & .60 \\
\hline Motor & -4.07 & 1.38 & -3.04 & 0.09 & .003 & -3.24 & 1.52 & -2.13 & 0.22 & .04 \\
\hline
\end{tabular}

Adjusted models include center, cardiopulmonary bypass duration, aortic cross-clamp time, use of deep hypothermic circulatory arrest, and Society of Thoracic SurgeryEuropean Association for Cardio-Thoracic Surgery category. BSID, Bayley Scales of Infant and Toddler Development third edition.

outcomes at discharge in neonates with birth-related hypoxic ischemic encephalopathy, and of periventricular white matter injury on 6-week head ultrasound imaging in premature infants. ${ }^{13,14,20}$ This study builds on the current literature by showing an association with circulating GFAP at the time of neonatal cardiac operations and neurodevelopmental assessment at 1 year.

\section{Congenital Heart Disease and Neurodevelopmental Outcomes}

The prevalence and severity of developmental disabilities increases with the complexity of congenital heart disease. Neonates and infants requiring open heart surgery for cyanotic or acyanotic defects are categorized as high risk for developmental disorders or disabilities. ${ }^{3,7}$ Etiologies postulated to explain such neurodevelopmental sequelae are diverse and include genetic syndromes, brain malformations, brain maturity, hypoxemic-ischemic insults, brain injury prenatally, during or after surgery, and socioeconomic and environmental factors. ${ }^{2,4,21,22}$

Although intraoperative factors receive the most attention, and would be the easiest to modify, it would be naive to place

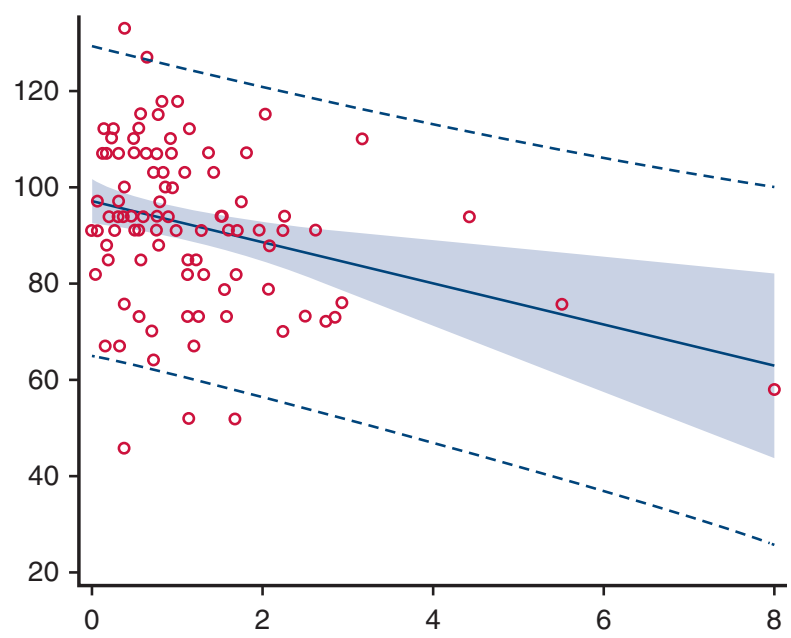

FIGURE 2. GFAP and Bayley Motor Score. Linear regression model showing the inverse association between GFAP levels $(\mathrm{ng} / \mathrm{mL})$ immediately after cardiopulmonary bypass on the $\mathrm{x}$-axis and BSID motor composite score at 12 months on the y-axis. all the blame on events in the operating room. Large studies involving infants with congenital heart disease show neurodevelopmental impairments are most highly associated with innate patient factors and general medical morbidities rather than specific techniques used intraoperatively. ${ }^{1,22,23}$ Despite this, in the Single Ventricle Reconstruction Trial, the largest prospective study to date of children undergoing the Norwood procedure at 15 centers in North America, the clinical center at which the Norwood procedure was performed emerged as an independent predictor of neurodevelopmental impairment. ${ }^{23}$ Clinical center remained an independent predictor although data on many potential risk factors, including details of perfusion techniques were included in their analysis and when centers were eliminated from the multivariable models one at a time. The authors opined that it was possible these differences were unmeasured variables in patient characteristics or perioperative management such as anesthetic agents. ${ }^{23}$ This highlights the need for a diagnostic means to acutely identify perioperative brain-specific injury to discriminate center-specific effects. Although not an objective of the current study we found a significant site-specific inverse relationship between higher post CPB GFAP values and lower BSID mean cognitive, language, and motor composite scores. Although many of the demographic characteristics and operating room procedures were similar there are some perfusion strategy differences between sites that could contribute. We have previously shown in a larger cohort, not exclusively focused on neonates, that perioperative GFAP was negatively associated with nadir oxygen delivery during CPB ${ }^{17}$ The amount of support or "flow" during CPB is empiric and immediately amenable as an actionable trial intervention, but was not recorded in this or many other cohorts. The centers also use different manufacturers for the bypass circuits and oxygenators. However, there are many other potential confounders that were not recorded including anesthetic, pain, and anxiolytic medications, socioeconomic status, and available health resources and early intervention programs that could contribute to these differences.

A metanalysis, including several interventional studies aimed at improving neurodevelopmental outcomes, showed that infants receiving cardiac surgery at younger than 6 months of age had cognitive and motor developmental 

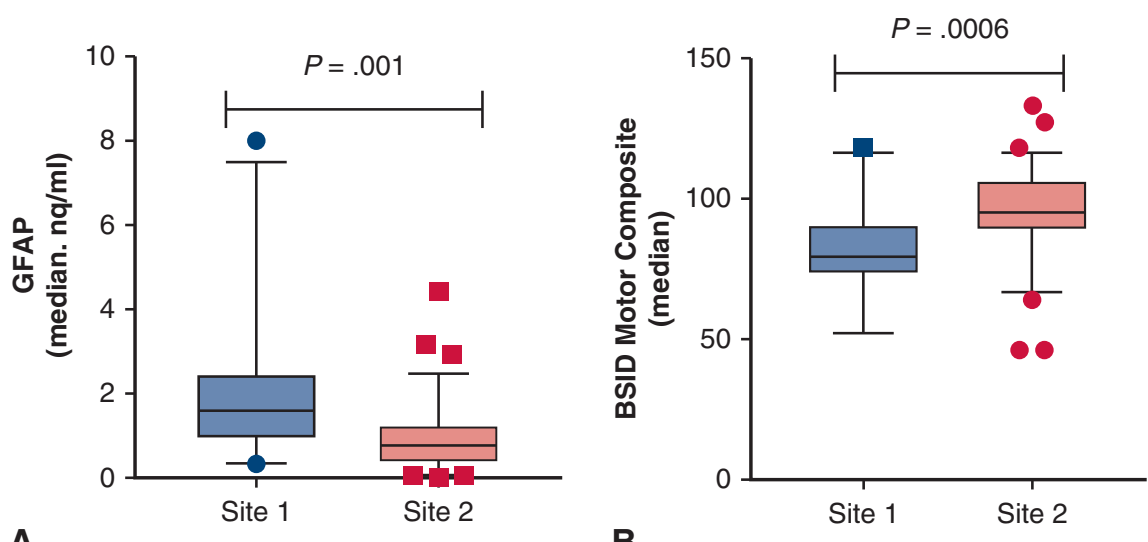

FIGURE 3. GFAP and Bayley Motor Score according to site. A, GFAP levels immediately after cardiopulmonary bypass and (B) BSID motor composite scores were different between the 2 sites. Patients from the institution (site 1) with higher GFAP levels had significantly lower BSID scores than the institution where patients had lower GFAP levels. The upper and lower borders of the box represent the upper and lower quartiles. The middle horizontal line represents the median. The upper and lower whiskers represent the maximum and minimum values of nonoutliers. Extra dots represent outliers. GFAP, Glial fibrillary acidic protein; BSID, Bayley Scales of Infant and Toddler Development third edition.

domains that were below the expected mean at all ages studied. The authors concluded that "more definitive outcomes are critical for parent counseling and the provision of timely intervention for the individual." ${ }^{3}$ Taken in whole one could envision a complex intertwined relationship in which genetics and innate patient factors result in brain vulnerability to the hemodynamic and physiologic stresses of the perioperative period. Therefore, the need to determine brain injury in real time to tease apart causal injury pathways for patientspecific interventions to improve outcome is paramount. If these findings can be confirmed by future studies GFAP could provide an invaluable tool as a means to focus, shorten, and decrease cost for interventional trials and ultimately reduce neurodevelopmental insult associated with the perioperative management of congenital heart disease.

\section{Limitation}

The results of this study must be viewed in light of its limitations. By design this study only included infants who completed a neurodevelopmental assessment at 12 months and therefore did not include children who died in the first year of life. This study included 2 institutions and although the BSID is a standardized test widely accepted to have good inter-rater reliability, we could not examine interrater reliability for individual testers for this study. There are growing concerns that the BSID underestimates neurodevelopmental disabilities with the greatest discrepancy in cognitive scores. ${ }^{24}$ This might explain this cohort's cognitive and language scores being slightly above the general population norm. Neurodevelopmental assessment at age 12 months might not be predictive of later outcomes and longer follow-up is necessary. ${ }^{22}$ These subjects were randomized to intraoperative steroid therapy as part of an interventional clinical trial. Because data collection is still ongoing we do not know if the trial intervention could have had on effect on GFAP levels and outcomes. Finally, although these findings are compelling and might constitute the basis for clearer exploration of neuroprotection going forward, a detailed determination of how patient- and center-specific perioperative factors contribute to elevated GFAP levels was beyond the scope of this work.

\section{CONCLUSIONS}

In summary, higher circulating GFAP levels at the time of neonatal cardiac surgery are independently associated with decreased BSID motor composite scores at 12 months. GFAP might serve as a diagnostic means to acutely identify perioperative brain-specific injury and serve as a benchmark of therapeutic efficacy for investigational treatments, provide early prognostic information for intervention, and discriminate center-specific effects for possible quality improvement initiatives. If these findings can be confirmed by future studies GFAP could provide an invaluable tool for reducing neurodevelopmental insult.

\section{Conflict of Interest Statement}

Dr Graham is a consultant for Bayer. Dr Everett is a consultant for Immunarray Inc. Immunarray Inc has licensed brain injury biomarkers from Johns Hopkins with Dr Everett as an inventor. All other authors have nothing to disclose with regard to commercial support.

The authors acknowledge Dawn L. Ilardi, $\mathrm{PhD}$, from Children's Healthcare of Atlanta for her contributions to the neurodevelopmental assessments. 


\section{References}

1. International Cardiac Collaborative on Neurodevelopment Investigators. Impact of operative and postoperative factors on neurodevelopmental outcomes after cardiac operations. Ann Thorac Surg. 2016;102:843-9.

2. Gaynor JW, Stopp C, Wypij D, Andropoulos DB, Atallah J, Atz AM, et al. Neurodevelopmental outcomes after cardiac surgery in infancy. Pediatrics. 2015;135:816-25.

3. Snookes SH, Gunn JK, Eldridge BJ, Donath SM, Hunt RW, Galea MP, et al. A systematic review of motor and cognitive outcomes after early surgery for congenital heart disease. Pediatrics. 2010;125:e818-27.

4. Gaynor JW, Nord AS, Wernovsky G, Bernbaum J, Solot CB, Burnham N, et al Apolipoprotein E genotype modifies the risk of behavior problems after infant cardiac surgery. Pediatrics. 2009;124:241-50.

5. Bellinger DC, Wypij D, duPlessis AJ, Rappaport LA, Jonas RA, Wernovsky G, et al. Neurodevelopmental status at eight years in children with dextrotransposition of the great arteries: the Boston circulatory arrest trial. J Thorac Cardiovasc Surg. 2003;126:1385-96.

6. Bellinger DC, Newburger JW, Wypij D, Kuban KC, duPlesssis AJ, Rappaport LA. Behaviour at eight years in children with surgically corrected transposition: the Boston circulatory arrest trial. Cardiol Young. 2009;19:86-97.

7. Marino BS, Lipkin PH, Newburger JW, Peacock G, Gerdes M, Gaynor JW, et al Neurodevelopmental outcomes in children with congenital heart disease: evaluation and management: a scientific statement from the American Heart Association. Circulation. 2012;126:1143-72.

8. Guingab-Cagmat JD, Cagmat EB, Hayes RL, Anagli J. Integration of proteomics, bioinformatics, and systems biology in traumatic brain injury biomarker discovery. Front Neurol. 2013;4:61

9. Honda M, Tsuruta R, Kaneko T, Kasaoka S, Yagi T, Todani M, et al. Serum glial fibrillary acidic protein is a highly specific biomarker for traumatic brain injury in humans compared with S-100B and neuron-specific enolase. J Trauma. 2010;69:104-9.

10. Kaneko T, Kasaoka S, Miyauchi T, Fujita M, Oda Y, Tsuruta R, et al. Serum glial fibrillary acidic protein as a predictive biomarker of neurological outcome after cardiac arrest. Resuscitation. 2009;80:790-4.

11. Papa L, Brophy GM, Welch RD, Lewis LM, Braga CF, Tan CN, et al. Time course and diagnostic accuracy of glial and neuronal blood biomarkers GFAP and UCHL1 in a large cohort of trauma patients with and without mild traumatic brain injury. JAMA Neurol. 2016;73:551-60.

12. Bayley NB. Scales of Infant and Toddler Development. 3rd ed. San Antonio, Tex: Harcourt Assessment Inc; 2006.

13. Bembea MM, Savage W, Strouse JJ, Schwartz JM, Graham E, Thompson CB, et al. Glial fibrillary acidic protein as a brain injury biomarker in children undergoing extracorporeal membrane oxygenation. Pediatr Crit Care Med. 2011;12:572-9.
14. Ennen CS, Huisman TA, Savage WJ, Northington FJ, Jennings JM, Everett AD, et al. Glial fibrillary acidic protein as a biomarker for neonatal hypoxic-ischemic encephalopathy treated with whole-body cooling. Am J Obstet Gynecol. 2011; 205:251.e1-7.

15. Hori D, Everett AD, Lee JK, Ono M, Brown CH, Shah AS, et al. Rewarming rate during cardiopulmonary bypass is associated with release of glial fibrillary acidic protein. Ann Thorac Surg. 2015;100:1353-8.

16. Hori D, Ono M, Rappold TE, Conte JV, Shah AS, Cameron DE, et al. Hypotension after cardiac operations based on autoregulation monitoring leads to brain cellular injury. Ann Thorac Surg. 2015;100:487-93.

17. Magruder JT, Hibino N, Collica S, Zhang H, Harness HL, Heitmiller ES, et al. Association of nadir oxygen delivery on cardiopulmonary bypass with serum glial fibrillary acid protein levels in paediatric heart surgery patients. Interact Cardiovasc Thorac Surg. 2016;23:531-7.

18. O'Brien SM, Clarke DR, Jacobs JP, Jacobs ML, Lacour-Gayet FG, Pizarro C, et al. An empirically based tool for analyzing mortality associated with congenital heart surgery. J Thorac Cardiovasc Surg. 2009;138:1139-53.

19. Brunetti MA, Jennings JM, Easley RB, Bembea M, Brown A, Heitmiller E, et al. Glial fibrillary acidic protein in children with congenital heart disease undergoing cardiopulmonary bypass. Cardiol Young. 2014;24:623-31.

20. Stewart A, Tekes A, Huisman TA, Jennings JM, Allen MC, Northington FJ, et al. Glial fibrillary acidic protein as a biomarker for periventricular white matter injury. Am J Obstet Gynecol. 2013;209:27.e1-7.

21. Riehle-Colarusso T, Autry A, Razzaghi H, Boyle CA, Mahle WT, Van Naarden Braun K, et al. Congenital heart defects and receipt of special education services. Pediatrics. 2015;136:496-504.

22. Goldberg CS, Lu M, Sleeper LA, Mahle WT, Gaynor JW, Williams IA, et al. Factors associated with neurodevelopment for children with single ventricle lesions. J Pediatr. 2014;165:490-6.e8.

23. Newburger JW, Sleeper LA, Bellinger DC, Goldberg CS, Tabbutt S, Lu M, et al Early developmental outcome in children with hypoplastic left heart syndrome and related anomalies: the single ventricle reconstruction trial. Circulation. 2012;125:2081-91.

24. Acton BV, Biggs WS, Creighton DE, Penner KA, Switzer HN, Thomas JH, et al Overestimating neurodevelopment using the Bayley-III after early complex cardiac surgery. Pediatrics. 2011;128:e794-800.

Key Words: congenital heart disease, cardiopulmonary bypass, glial fibrillary acidic protein 